\title{
KAJIAN TINGKAT KEBISINGAN PADA RUANG PAMERAN TETAP DI MUSEUM XY JAKARTA
}

\author{
Anastasia Cinthya ${ }^{1}$ \\ ${ }^{1}$ Desain Interior, Universitas Tarumanagara, Jakarta \\ Email:anastasiag@fsrd.untar.ac.id
}

\begin{abstract}
A common issue in the permanent exhibition hall in the museum is how it is quiet when visitors are silent and noisy when visitors are loud. A very quiet atmosphere creates a tense atmosphere in the permanent exhibition hall. Conversely, a noisy atmosphere will make visitors feel uncomfortable while being in the permanent exhibition hall. The sound intensity of $<20 \mathrm{~dB}$ in a room is deemed quiet, and the atmosphere of the room will feel tense. However, if the sound intensity in a room exceeds $85 \mathrm{~dB}$, then the sound condition in the room is deemed noisy. Quiet and noisy room conditions are uncomfortable for the hearing of those doing activities in said room. To find out the average sound intensity in the permanent exhibition room of the National Museum of Indonesia, this study uses Sound Level Meter measuring instrument, as the main tool. Another research aid in the form of a Laser Length Meter is used to measure the distance of the source of the sound. The results of the recording and measurement are analyzed quantitatively using standard audio comfort. The aims of this study are to obtain acoustic data related to sound quality, acoustic-affecting materials used for the construction of the room, and data of audio equipment owned by the XY Museum. In this study, it is also necessary to obtain data on the density of visitors in the Permanent Exhibition Room which largely contributes to noise level. By knowing these conditions, it can be used as a reference in arranging the permanent exhibition room of the museum.
\end{abstract}

Keywords: Threshold value, Noise level, Museum

\begin{abstract}
ABSTRAK
Masalah umum pada ruang pameran tetap di museum adalah sunyi saat pengunjung sepi dan gaduh saat pengunjung ramai. Suasana yang sangat sunyi akan membuat suasana mencekam dalam ruang pameran tetap. Sebaliknya, suasana gaduh akan membuat pengunjung tidak nyaman selama berada dalam ruang pameran tetap. Adapun ambang batas Kuat suara $<20$ dB dalam suatu ruangan termasuk sunyi, susana ruangan akan terasa mencekam. Namun bila kuat suara dalam suatu ruangan melebihi 85 dB, maka kondisi suara dalam ruangan tersebut termasuk bising. Kondisi ruangan yang sunyi dan kondisi ruangan yang bising, akan tidak nyaman secara audio untuk manusia beraktivitas didalam ruangan tersebut. Untuk mengetahui rata-rata kuat suara didalam ruang pameran tetap Museum Nasional Indonesia, penelitian ini menggunakan alat ukur yang Sound Level Meter, sebagai alat utamanya. Dan menggunakan alat bantu penelitian berupa Laser Length Meter untuk mengukur jarak sumber suaranya. Hasil perekaman dan pengukuran dianalisis secara kuantitatif dengan menggunakan standar kenyamanan audio. Hasil penelitian ini untuk mendapatkan data akustik yang berkaitan dengan kualitas suara, material pembentuk ruang yang mempengaruhi akustik, serta data perlengkapan audio yang dimiliki oleh Museum XY. Pada penelitian ini juga diperlukan data tingkat kepadatan pengunjung pada Ruang Pameran Tetap yang berpotensi besar terhadap tingkat kebisingan. Dengan mengetahui kondisi tersebut maka dapat dijadikan acuan nantinya dalam penataan ruang pameran tetap museum.
\end{abstract}

Kata kunci : Nilai ambang batas, Tingkat kebisingan, Museum

\section{PENDAHULUAN}

Museum adalah tempat dipamerkannya benda tangible (fosil, artefak) dan intangible (nilai, tradisi, norma). Peran dan fungsi utama museum adalah sebagai lembaga edukatif. Tantangannya bagaimana visi misi museum sejalan dengan harapan masyarakat. Pada umumnya museum-museum di Indonesia tak mampu menyajikan model edukasi atau alih pengetahuan secara menarik, informatif, dan atraktif kepada masyarakat.(Tjahjono, 2018; Yudiantika, Pasinggi, Sari, \& Hantono, 2013)

Museum sebagai fasilitas publik berfungsi sebagai lembaga konservasi, edukasi, dan rekreasi. Untuk itu perlu suatu penataan yang dapat dinikmati oleh seluruh golongan usia. 
Suasana ruangan yang 'ramah', akan membuat pengunjung nyaman selama berada dalam ruangan-ruangan pameran tetap di museum (Syafrudin \& Setijanti, 2017). Salah satu kenyamanan tersebut adalah kenyamanan secara audio. Dimana ruangan tidak terlalu sunyi saat sepi pengunjung, yang dapat menimbulkan rasa mencekam yang menyebabkan pengunjung enggan menjelajah keseluruh ruangan (Chen, Zhang, Pan, \& Cong, 2014). Dan tidak pula terlalu bising disaat pengunjung ramai, sehingga merusak konsentrasi pengunjung yang ingin menikmati satu persatu koleksi materi yang dipamerkan (Aji, 2017).

Untuk itu, peneliti merasa perlu untuk mengetahui tingkat kebisingan yang berkaitan dengan material pembentuk ruang, kualitas suara, perlengkapan audio, serta alur/ tingkat kepadatan pengunjung didalam ruang pameran tetap Museum XY. Dimana hasil dari penelitian ini dapat menjadi masukan bagi pengelola Museum XY kedepan untuk dapat menata akustik di ruang pameran tetap sehingga setiap ruangan akan mendapatkan kenyamanan secara audio, yang pada akhirnya akan meningkatkan kepuasan pengunjung Musuem XY terhadap fasilitas pameran tetapnya (Sezer, Arslan, \& Çahantimur, 2014; Sezer \& Erbil, 2016).

Awalnya, bangunan Museum XY merupakan rumah tinggal keluarga XY, baru pada tahun 1998 rumah di Jalan Keuangan Raya No. 19 Cilandak Barat Jakarta Selatan di serahkan kepada Pemerintah Republik Indonesia melalui Direktorat Jenderal Kebudayaan cq. Direktorat Permuseuman. Bangunan rumah dua tingkat seluas $\pm 600 \mathrm{~m} 2$ dan luas tanah $\pm 450 \mathrm{~m} 2$. Rumah ini kemudian direnovasi agar dapat difungsikan sebagai museum. Pada tanggal 25 September 2001 Museum XY diresmikan oleh Menteri Kebudayaan dan Pariwisata Drs. I Gede Ardika. Koleksi Museum XY terdiri dari koleksi lukisan dan koleksi pribadi pelukis XY berupa patung, topeng, wayang, senjata dan sebagainya. Jumlah koleksi museum yang dihibahkan berdasarkan data yang ada sebanyak 123 buah, sedangkan koleksi pribadi (barang dan benda seni) milik XY sebanyak 720 buah, dan buku-buku/majalah \pm 3000 buah.

Setiap ruang pameran tetap di museum membutuhkan penataan akustik untuk pengkondisian tata suara di dalam ruang pameran(Arai et al., 2012). Tata suara yang diatur dapat membangkitkan atmosfir ruangan sesuai dengan story line yang diharapkan (Schoer, 2009). Selain itu juga kondisi didalam ruangan tidak akan terlalu sunyi. Sebaliknya, dengan menggunakan material yang dapat menyerap suara akan dapat mengurangi gaung atau gema didalam ruangan (Ogunsote, 2014). Secara audio, pengunjung akan merasakan nyaman dalam menikmati materi koleksi yang dipamerkan.

Bising merupakan salah satu polutan yang paling sering ditemukan di lingkungan kerja dan merupakan risiko kerja yang harus diwaspadai. Tujuan dari penelitian ini adalah :

1) Untuk mengetahui kuat suara di dalam ruang pameran tetap.

2) Untuk mengetahui perlengkapan audio maupun visual didalam ruang pameran tetap.

3) Untuk mengetahui alur dan tingkat kepadatan pengunjung didalam ruang pameran tetap.

\section{METODE PENELITIAN}

Untuk mengukur kebisingan di lingkungan kerja dapat dilakukan dengan menggunakan alat Sound Level Meter (Peelle, Eason, Schmitter, Schwarzbauer, \& Davis, 2010). Ada tiga cara atau metode pengukuran akibat kebisingan di lokasi kerja.

1. Pengukuran dengan titik sampling

Pengukuran ini dilakukan bila kebisingan diduga melebihi ambang batas hanya pada satu atau beberapa lokasi saja. Pengukuran ini juga dapat dilakukan untuk mengevaluasi kebisingan yang disebabkan oleh suatu peralatan sederhana, misalnya Kompresor/generator. Jarak pengukuran dari sumber harus dicantumkan, misal 3 meter dari ketinggian 1 meter. Untuk itu diperlukan alat bantuan berupa Laser Length Meter. Selain itu juga harus diperhatikan arah mikrofon alat pengukur yang digunakan. 
2. Pengukuran dengan peta kontur

Pengukuran dengan membuat peta kontur sangat bermanfaat dalam mengukur kebisingan, karena peta tersebut dapat menentukan gambar tentang kondisi kebisingan dalam cakupan area. Pengukuran ini dilakukan dengan membuat gambar isoplet pada kertas berskala yang sesuai dengan pengukuran yang dibuat. Biasanya dibuat kode pewarnaan untuk menggambarkan keadaan kebisingan, warna hijau untuk kebisingan dengan intensitas dibawah $85 \mathrm{dBA}$ warna orange untuk tingkat kebisingan yang tinggi diatas $90 \mathrm{dBA}$, warna kuning untuk kebisingan dengan intensitas antara 85 - $90 \mathrm{dBA}$.

3. Pengukuran dengan Grid

Untuk mengukur dengan Grid adalah dengan membuat contoh data kebisingan pada lokasi yang di inginkan. Titik-titik sampling harus dibuat dengan jarak interval yang sama diseluruh lokasi. Jadi dalam pengukuran lokasi dibagi menjadi beberpa kotak yang berukuran dan jarak yang sama, misalnya : 10 x $10 \mathrm{~m}$. kotak tersebut ditandai dengan baris dan kolom untuk memudahkan identitas.

Dua hal utama yang mempengaruhi kualitas data hasil penelitian, yaitu kualitas instrumen penelitian, dan kualitas pengumpulan data. Kualitas instrumen penelitian berkenaan dengan validitas dan reliabilitas instrumen dan kualitas pengumpulan data berkenaan ketepatan cara-cara yang digunakan untuk mengumpulkan data (Sugiyono, 2008)

Perlu diketahui bahwa pengukuran kenyamanan terhadap kenyamanan akustik dapat dilihat dari 2 sisi, yaitu sisi objektif maupun subyektif (Fuchs, 2013; Lucchi, 2016). Penilaian objektif tentunya berdasarkan kepada besaran-besaran yang bersifat objektif yaitu besaran-besaran fisika, misalnya besaran 'sound pressure level' dari sumber suara, besaran waktu dengung ruangan atau juga 'directivity' dari mikrophone (dalam hal ini mikrophone bertindak sebagai penerima suara) (Ealo et al., 2008). Sementara itu penilaian subjektif pada umumnya berdasarkan kepada 'subjective preference' dari orang yang menilainya, meskipun penilaian yang dilakukan tersebut sering juga didasarkan kepada besaran-besaran fisika, misalnya seseorang lebih menyukai 'speaker A' dibandingkan dengan 'speaker B' akibat adanya (Mills, 2009).

Hari pelaksanaan pengambilan data akan dilaksanakan pada hari Sabtu, dimana pada hari tersebut menurut informasi dari pihak Museum Nasional adalah hari dimana jumlah pengunjung terbilang ramai bila dibandingkan dengan hari Senin - Jumat. Pengukuran pada satu titik akan dilakukan tiga kali, dengan interval waktu per lima menit. Hal ini dibutuhkan untuk menangkap fenomena suara yang terjadi pada tiap titik pengukuran. Alat yang digunakan untuk pengukuran adalah Sound level Meter dan Laser Length Meter.

Penelitian ini menggunakan dua metode pengumpulan data, yaitu pengukuran dan kuesioner(Barron, 2009). Sehingga metode analisis yang dilakukan pun ada dua metode, dimana data hasil kuesioner akan dilakukan analisis dengan program SPSS.

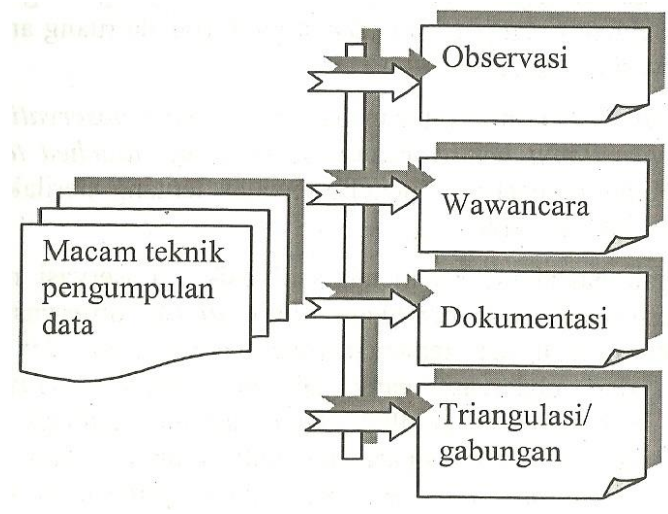


Gambar 1: Diagram Teknik Pengumpulan Data(Sugiyono, 2008)

Untuk memfokuskan penelitian, sebagai mana ditunjukan pada gambar denah diatas, maka pada tahap observasi peneliti telah menentukan titik-titik didalam ruang pameran tetap yang akan diukur intensitas suaranya.

Data dari hasil pengukuran akan dianalisis dengan metode menghitung rata-rata dari hasil pengukuran pada tiap titik. Kemudian diinput data rata-rata hasil pengukuran dititik A hingga titik V. Hasil pengukuran dilokasi akan dihitung reratanya dan dikelompokan berdasarkan referensi tingkat kebisingan dari IATA. Zonasi dari IATA, menyatakan bahwa ruangan yang tenang namun tidak terlalu sunyi dimana kegiatannya sebagaimana kegiatan penelitian adalah pada kisaran 35 - $45 \mathrm{~dB}$, dan zonasi area dimana kegiatannya sebagaimana kegiatan pendidikan dan rekreasi dimana ada kegiatan bercakap-cakap berada pada kisaran 45 - $55 \mathrm{~dB}$.

\section{HASIL DAN BAHASAN}

Ruangan Pameran Tetap berukuran 875 (P) x 594 (L) cm, dengan ketinggian ruangan 300 $\mathrm{cm}$, berada dilantai dasar. Ruangan ini menggunakan bahan lantai Ganito Tile ukuran $60 \times 60 \mathrm{~cm}$ finishing kilap, Partisi menggunakan Gypsum finishing cat dinding, sedangkan untuk plafond menggunakan Gypsum accoustic board. Sedangkan untuk furnitur yang ada pada ruangan yaitu 2 buah vitrin yang diletakkan pada tengah ruangan. Vitrin adalah sebuah lemari yang berukuran $120 \mathrm{~cm} \times 60 \mathrm{~cm}$, vitrin tersebut mempamerkan karya foto dan manuskrip puisi yang diciptakan oleh XY. Pengukuran dilakukan pada hari Sabtu, 25 November 2017, pukul 10.00 - 11.30 WIB dengan menentukan 12 titik pengukuran yang berjarak $120 \mathrm{~cm}$ antar semua titik(Herwanto, 2016).

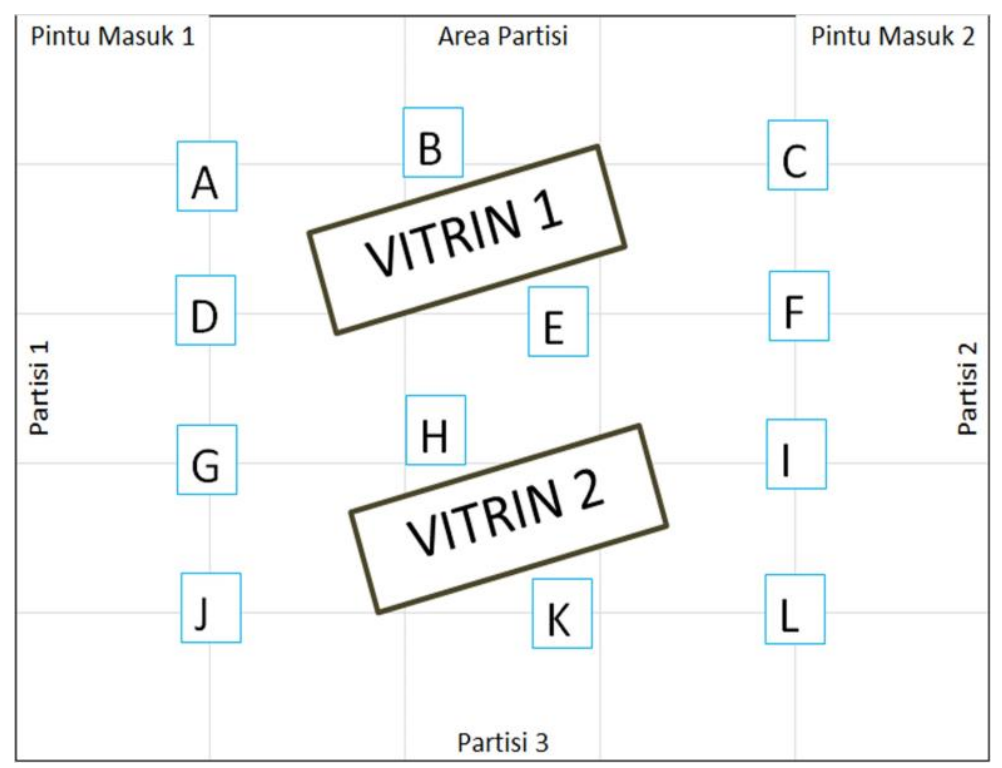

Gambar 2: Titik A - L Sebagai Posisi Pengukuran 
Tabel 1 .

Tabel Hasil Pengambilan Data Tingkat kebisingan

\begin{tabular}{|c|c|c|c|c|c|c|c|}
\hline \multicolumn{8}{|c|}{ PENGAMBILAN DATA TINGKAT KEBISINGAN } \\
\hline \multicolumn{8}{|c|}{ Hari/Tanggal: Sabtu, 25 November 2017} \\
\hline \multicolumn{8}{|c|}{ Lokasi: Ruang Pameran tetap, Museum Basoeki Abdullah } \\
\hline \multicolumn{2}{|c|}{ Penginput Data: } & \multicolumn{3}{|c|}{ 1. Anastasia Cinthya Gani } & & & \\
\hline & & \multicolumn{3}{|c|}{ 2. Heru budi Kusuma } & & & \\
\hline No & Area Pengambilan Data & Kode & Jam & Sumber Suara & Jumlah & Jarak (M) & Kuat Suara (dB) \\
\hline \multirow{2}{*}{\multicolumn{2}{|c|}{1 Pintu Masuk (1) }} & A & 10,18 & $A C$ & 2 & 3,5 & \\
\hline & & & & Manusia & 5 & 2 & 67 \\
\hline \multirow{2}{*}{\multicolumn{2}{|c|}{2 Area Partisi (1) }} & B & 10,22 & & 2 & 3,3 & \\
\hline & & & & Manusia & 5 & 3 & 65,7 \\
\hline \multicolumn{2}{|r|}{3 Pintu Masuk (2) } & c & 10,26 & $A C$ & 2 & 3,6 & 50 \\
\hline \multicolumn{2}{|c|}{4 Partisi (1) } & D & 10,32 & $A C$ & 2 & 3,8 & 47 \\
\hline \multirow{2}{*}{\multicolumn{2}{|c|}{5 Display (1) }} & $\mathrm{E}$ & 10,36 & & 2 & 4,2 & \\
\hline & & & & Manusia & 2 & 4 & 57 \\
\hline \multicolumn{2}{|c|}{6 Partisi (2) } & $\mathrm{F}$ & 10,42 & $A C$ & 2 & 4,4 & 51 \\
\hline \multicolumn{2}{|c|}{7 Partisi (1A) } & G & 11,00 & $A C$ & 2 & 4,2 & 48 \\
\hline \multicolumn{2}{|c|}{ 8Display (2) } & H & 11,04 & $A C$ & 2 & 3,8 & 50 \\
\hline \multicolumn{2}{|c|}{9 Partisi $(2 \mathrm{~A})$} & I & 11,11 & $A C$ & 2 & 4,2 & 48 \\
\hline \multicolumn{2}{|c|}{10 Partisi (3A) } & $\mathrm{J}$ & 11,19 & $A C$ & 2 & 3,6 & 46 \\
\hline \multicolumn{2}{|c|}{11 Partisi (3B) } & $\mathrm{K}$ & 11,23 & $A C$ & 2 & 3,5 & 49 \\
\hline \multicolumn{2}{|c|}{12 Partisi (3C) } & $\mathrm{L}$ & 11,30 & $A C$ & 2 & 3,7 & 50 \\
\hline & JUMLAH & & & & & & 628,7 \\
\hline & RATA-RATA & & & & & & 52,39 \\
\hline
\end{tabular}

Jumlah pengunjung Museum XY pada hari Sabtu tidaklah banyak. Setidaknya selama kami melakukan pengukuran ada 12 orang pengunjung yang datang bergantian ke ruang 
pameran tetap. Kondisi existing ruangan terhadap tingkat kebisingan relatif tenang, karena tidak ada sumber suara yang mempengaruhi akustik ruangan kecuali keberadaan 2 unit AC Cassette yang terpasang dilangit-langit.

Dari hasil observasi dan pengukuran, diperoleh data sebagai berikut:

- Luas ruangan 8,75 x 5,94=51,975 m2

- Posisi ruang pameran berjarak cukup jauh dari jalan lingkungan

- Material pembentuk ruang; lantai dari bahan keras, partisi dan langit-langit dari bahan lunak

- Sumber suara dalam ruangan berasal dari 2 unit AC Cassette yang dipasang pada langitlangit dengan ketinggian $300 \mathrm{~cm}$.

- Tingkat kebisingan terendah: $47 \mathrm{~dB}$, tingka kebisingan tertinggi: $67 \mathrm{~dB}$, dan rata-rata tingkat kebisingan dari 12 titik pengukuran: 52,39 dB.

- Jumlah pengunjung tidak banyak, dan rata-rata usia pengunjung dari hasil pengamatan adalah diatas 12 tahun.

Dari hasil pengukuran dan bahasan diatas, maka dapat dinyatakan bahwa Tingkat Kebisingan Ruang Pameran Tetap di Museum XY berada pada kategori 'Nyaman' atau pada kondisi 'Kenyamanan Audio' dikarenakan:

- Posisi ruangan yang jauh dari jalan lingkungan, menyebabkan terjadinya reduksi noise terhadap ruangan (Rådsten-Ekman, Axelsson, \& Nilsson, 2013).

- Jumlah pengunjung yang tidak ramai, sehingga tidak berpotensi menimbulkan kegaduhan secara audio (ARDHANA RESWARI, Budi Sardjono, \& Suyono, 2015).

- Pengunjung yang datang, rata-rata berusia diatas 12 tahun sehingga sudah memahami ketertiban diruang publik.

- Sumber suara dalam ruangan didominasi oleh dengung mesin unit AC Cassette yang terpasang dilangit-langit ruangan.

- Tingkat kebisingan dalam ruangan dari 12 titik pengukuran diperoleh data tingkat kebisingan terendah $46 \mathrm{~dB}$, tertinggi $67 \mathrm{~dB}$, dan rata-rata 52,39 dB (Fenny \& Kurnia, 2013).

\section{KESIMPULAN DAN SARAN}

Faktor akustik seringkali terlupakan dalam desain berbagai museum, namun adakalanya akustik tersebut akan menjadi bagian yang sangat krusial seperti di ruang pamer. Secara umum kualitas akustik dari museum ini sudah cukup baik, namun perlu diperhatikan juga masalah penempatan furnitur ruang pamer. Pengendalian bising ruang pamer kedepannya harus dimulai dengan perencanaan letak yang baik, dengan memisahkan ruang pamer dengan ruangan lain atau metakkannya jauh dari semua sumber bising eksterior dan interior dan sumber-sumber getaran, seperti lalu lintas kendaran yang bising. Sistem ventilasi dan pengkondisi udara untuk suatu ruang pamer harus dirancang sedemikian rupa hingga tingkat bising yang dihasilkan hanya pada ambang batas $5 \mathrm{~dB}$ sampai $15 \mathrm{~dB}$ di bawah tingkat bising latar belakang yang ditentukan dalam kriteria bising. Selain dari sisi desain, pengendalian bising juga bisa didapatkan dari pengendalian jumlah pengunjung dan karakteristik pengunjung.

\section{Ucapan Terima Kasih}

Ucapan terima kasih diberikan kepada pihak Museum XY atas waktu dan tempat yang diberikan kepada peneliti untuk berkarya, terima kasih juga diucapkan kepada DPPM Universitas Tarumanagara atas dukungan sehingga penelitian ini dapat berlangsung dengan baik.

\section{REFERENSI}


Aji, K. B. (2017). Analisis Kelayakan Museum Sasmitaloka Panglima Besar Jenderal Sudirman dalam Perspektif Pariwisata. Tourisma, 1(1), 55-68.

Arai, T., Amino, K., Sonu, M., Yasu, K., Igeta, T., Tomaru, K., \& Kasuya, M. (2012). Hands-on speech science exhibition for children at a science museum. Paper presented at the Third Workshop on Child, Computer and Interaction.

Ardhana R., A., Budi Sardjono, A., \& Suyono, B. (2015). Perpustakaan Umum Kota Semarang. Fakultas Teknik UNDIP.

Barron, M. (2009). Auditorium acoustics and architectural design: Routledge.

Chen, S., Zhang, D. X., Pan, X. X., \& Cong, Y. (2014). The acoustic test report of three outdoor courtyard in Shenyang palace museum. Paper presented at the Applied Mechanics and Materials.

Ealo, J. L., Seco, F., Prieto, C., Jiménez, A. R., Roa, J., Koutsou, A., \& Guevara, J. (2008). Customizable field airborne ultrasonic transducers based on electromechanical film. Paper presented at the Ultrasonics Symposium, 2008. IUS 2008. IEEE.

Fenny, S. W. H. C. I., \& Kurnia, D. (2013). Perancangan Interior Museum Musik Klasik Berbasis Media Berteknologi Tinggi untuk Anak-anak di Surabaya. Intra, 1(2).

Fuchs, H. V. (2013). Applied Acoustics: Concepts, Absorbers, and Silencers for Acoustical Comfort and Noise Control: Alternative Solutions-Innovative Tools-Practical Examples: Springer Science \& Business Media.

Herwanto, T. (2016). Perancangan Interior Museum Benteng Van Der Wijck, Gombong, Kebumen. Institut Seni Indonesia Yogyakarta.

Lucchi, E. (2016). Multidisciplinary risk-based analysis for supporting the decision making process on conservation, energy efficiency, and human comfort in museum buildings. Journal of Cultural Heritage, 22, 1079-1089.

Mills, L. (2009). Theatre Voice: Practice, Performance and Cultural Identity. South African Theatre Journal, 23(1), 84-93.

Ogunsote, O. (2014). Futa Technology Museum. Federal University Of Technology, Akure.

Peelle, J. E., Eason, R. J., Schmitter, S., Schwarzbauer, C., \& Davis, M. H. (2010). Evaluating an acoustically quiet EPI sequence for use in fMRI studies of speech and auditory processing. Neuroimage, 52(4), 1410-1419.

Rådsten-Ekman, M., Axelsson, Ö., \& Nilsson, M. E. (2013). Effects of sounds from water on perception of acoustic environments dominated by road-traffic noise. Acta Acustica united with Acustica, 99(2), 218-225.

Schoer, H. (2009). The sounding museum cultural soundscapes as a tool in museum education. Canadian Acoustics, 37(3), 100-101.

Sezer, F. Ş., Arslan, T. V., \& Çahantimur, A. (2014). Evaluation of User Satisfaction in Relation to Comfort Conditions in Shopping Malls: Bursa as a Case. Uludağ University Journal of The Faculty of Engineering, 19(1), 81-95.

Sezer, F. Ş., \& ERBILL, Y. (2016). Investigation Of Physical Comfort Conditions And Users'satisfaction In Cottage Hospitals: The Case Of Nilufer/Bursa, Turkey. The Online Journal of Science and Technology-July, 6(3).

Sugiyono. (2008). Metode penelitian pendidikan:(pendekatan kuantitatif, kualitatif dan $R \& D$ ): Alfabeta.

Syafrudin, U., \& Setijanti, P. (2017). Maritime Living Museum: Eksplorasi Ruang Ekspose Pesisir. Jurnal Sains dan Seni ITS, 6(2), G407-G411.

Tjahjono, B. D. (2018). Memimpikan Museum yang Menarik Pengunjung. Berkala Arkeologi SANGKHAKALA, 13(26), 166-175.

Yudiantika, A. R., Pasinggi, E. S., Sari, I. P., \& Hantono, B. S. (2013). Implementasi Augmented Reality Di Museum: Studi Awal Perancangan Aplikasi Edukasi Untuk Pengunjung Museum. 